\title{
Community-University Health Research Partnerships
}

\section{Challenges and Concrete, Plain Language Strategies for Community Engagement in Research}

\author{
Janet Page-Reeves and Lidia Regino
}

\begin{abstract}
Aвstract: In recent years, there have been positive changes to the health research landscape, with increasing interest amongst community organisations and university investigators in establishing research partnerships and with more funding opportunities for communityengaged work. However, creating a community-university partnership requires new skills, new types of knowledge, and new ways of creating and maintaining relationships. On both sides of the research equation, people are looking for guidance. The discussion here uses our experience to offer concrete tips in plain language for strategies that can be used to build capacity for community-university partnerships for organisations and researchers in pre-partnership and early partnership stages. We comment on debates about epistemology and knowledge production in research and how anthropologists are well positioned to contribute to this process.
\end{abstract}

KeYwORDs: capacity-building, community engagement, community-university partnership, lessons learnt, participatory research

\section{The Context for Community-Engaged Health Research}

Community-engaged health research of different sorts, including but not limited to patient engagement (PE), community-based participatory research (CBPR), participatory action research (PAR), and patient and public involvement (PPI), is increasingly embraced by a wide variety of health research stakeholders globally (Brett et al. 2014; Gallivan et al. 2012; Wallerstein et al. 2017). Of course, anthropologists have historically tended to have a strong connection to the communities where they work, given the nature of the ethnographic fieldwork enterprise. In recent years, calls to rethink the role or relevance of anthropology have inevitably been tied to the way that the anthropologist develops relationships with community members and deploys anthropological knowledge and expertise outside of academia (e.g. Bangstad et al. 2017, Landi 2017; Shakya and Clammer 2017). Importantly, in health research, interest in community engagement has also come from the people who participate in research studies who want to be involved as more than just research 'subjects'. Community organisations, community members, and patients see potential benefits to communityuniversity health research partnerships in terms of health-related knowledge production, organisational and community capacity-building, and access to new streams of resources. Enthusiasm for community, patient and public engagement and involvement amongst health researchers of all disciplines is also on the rise, reflecting an expanding understanding of the multidimensional nature of the research enterprise and 
emerging opportunities for funding for engaged research. New requisites for engagement emanate from the politics of health policy reform, funders eager to demonstrate 'cutting-edge' approaches, newly adopted university mission statements to improve health more broadly, evolving ideas about research equity and social justice, and the daunting spectre of trying to understand and address complex health problems, social determinants of health, and the continuing or even increasing production of health disparities.

\section{Conflicting Dynamics}

The funding piece of the dynamics of communityengaged health research is proving to be a particularly influential catalyst for change. Funders that once ignored, dismissed or even in reality tacitly disallowed community engagement now often rhetorically endorse or even require community involvement or patient engagement in identifying research priorities, in defining research questions, or in conducting research and disseminating results. ${ }^{1}$ As a result, community engagement is now entering into mainstream consciousness in health research, and, although it is still peripheral in terms of the power relationships that define the health research enterprise, community engagement has become a fashionable part of the health research narrative. Not insignificantly, there is a somewhat 'trendy' vibe associated with community engagement processes. Researchers who have networks in the community or who work closely with community organisations have a certain élan in settings where investigators are more likely to work in labs or to have little personal interaction with the participants in a study. You might imagine this dynamic as a sort of localisation of the classic 'exoticness' that has always been attributed to the anthropologist and the anthropological enterprise. In health research, anything outside the university or the purview of the well-regulated setting of the randomised controlled trial can appear as somewhat unable to be controlled for ('wild') or unpredictable things that are traditionally seen as being antithetical to 'scientific research'. Author \#1 (Page-Reeves), an anthropologist, has been told by other researchers that community-engaged research methods are not scientific, and she was once told that the approach she proposed for a project would produce 'too much data' - a situation that the researcher believed would be untenable from a scientific perspective. Clearly, existing research power hierarchies within the academy and in relation to health policy are not shifting in any cataclysmic way in terms of giving alternative ways of understanding the world more legitimacy in the quantitative, positivistic and medical-centric arena of health research. That is still a work in progress.

Moreover, despite interest, enthusiasm, rhetoric, trendiness and even some funding, practical barriers and scientific challenges still exist. For example, there continues to be a significant gap between targeted funding opportunities that openly embrace community engagement and the structure of the more general funding process, where the lion's share of health research funds resides. Timelines for proposal development are also not conducive to communityengaged research. The allotted time between the release of a funding announcement and the subsequent submission due dates is almost never sufficient for meaningful community engagement (even when it is required for the submission), nor does the amount of time allocated for funded research realistically take into consideration the extra time required for working with community-engaged principles. Such practical considerations often make it difficult to develop a meaningful and scientifically competitive community-engaged research proposal. And while opportunities for funding for community-engaged health research are expanding, requests for proposals (RFPs) that require community engagement inevitably also require 'scientific rigour', which generally involves the use of 'reliable and valid' research instruments (such as questionnaires or surveys). Yet there remains virtually no funding mechanism to allow for the development of instruments through a community-engaged process. Therefore, by default community-engaged projects end up having to use instruments that were developed using traditional, mainstream research approaches without including community perspectives or input. Such instruments, despite having been validated through an accepted statistical process, are therefore less likely to generate results that will reveal subtle dynamics at play in complex health problems. To what extent, then, are such 'reliable and valid' instruments actually scientific? In our experience, while the questions on an existing instrument may be statistically valid, they are often not the right questions. And anthropologists know that the only way to figure out what the right questions are is to talk to people and to involve them in helping think about the process and the issues at hand. Nonetheless, not only is it nearly impossible to find funding for community-engaged tool development and validation, but research designs that include more heuristic, discovery-based, hypothesisgenerating approaches that are common in commu- 
nity-engaged research - and which are also common in anthropology - continue to face an uphill battle in the grant review process of large health research funders interested in intervention/implementation research that involves randomly assigning subjects to different arms of a study.

Similarly, budget items that would make community participation in research feasible (such as explicit and equitable compensation for community organisations as research partners or as research sites) or that would support community engagement processes (such as food for community meetings, trainings for community members [Page-Reeves et al. 2017a], or professional-level stipends for community advisors, mentors or partners) are often prohibited by funders' fiscal guidelines. Without adequate and realistic financial supports, community-engaged research becomes more challenging or even impossible. Moreover, grant reviewers often lack the epistemological sensibility that would make it possible for them to accurately evaluate the merits of community-engaged project proposals, or they do not have the practical experience with community-engaged research practices to understand the rationale for many features of community-engaged research design. Without this reviewer expertise, it remains unlikely that community-engaged proposals can be reviewed appropriately or that they will be considered competitive in mainstream grant review contexts. And even if a community-engaged research project is funded, there are enormous infrastructural barriers related to contracts, trainings and required certifications (Page-Reeves 2018; Page-Reeves et al. 2017a; Page-Reeves et al. 2018); electronic access to databases and email accounts necessary for research (Page-Reeves 2018); and ownership of data (PageReeves et al. 2017) that are not easily surmounted or changed. Even when there is evidence that physical infrastructure or bureaucratic infrastructural practice is flawed or actually absurd, trying to convince university bureaucrats of the need for change can feel like a walk through a Kafka novel.

\section{A Shifting Landscape}

Yet while it is clear that a full paradigm shift has certainly not yet occurred and that significant barriers to funding and implementing communityengaged health research remain, the scientific and funding landscape is shifting, if not fundamentally, then certainly in some profound and practical ways. Reflected in the new willingness of funders to support some community-engaged research, community engagement is now considered, at the very least, to be within the domain of mainstream health research (e.g. Wallerstein et al. 2017) rather than outside of it. In the past, it was seen to be heretical to investigatorinitiated and investigator-driven norms and standards, either viewed a priori as inherently unscientific, or merely deemed entirely irrelevant. And, ironically, contrary to fears of being 'unscientific' and to beliefs about 'bad science' that were pervasive in the mainstream health research community and that were routinely used to justify denying funding requests for community-engaged studies - and that were used by high-impact health journals to reject manuscripts that reported findings from studies that used an engaged design - community-engaged research approaches have been shown definitively to actually improve rather than diminish the scientific quality of research results (e.g. Balazs and MorelloFrosch 2013; Haywood et al. 2015).

Patients, community members, communities and community organisations have played a significant role in shifting the health research paradigm to begin to accept community-engaged research approaches. Increasing interest in community engagement in health research amongst neighbourhoods or populations that would be involved in study procedures or affected by research results has been an important catalyst for changing the funding landscape. In many cases, patients, communities and community-based organisations are demanding a seat at the table and policymakers who need to be responsive to their constituencies have required that public agencies do more to include community and patient perspectives in funding priorities and processes for health research. Private sector funders frustrated with investments in health promotion that have failed to produce desired changes have embraced theoretical frameworks such as collective impact (Kania and Kramer 2011), cross-sector collaboration (Towe et al. 2016) and a culture of health (Trujillo and Plough 2016) which make it necessary for researchers to get out of ivory tower silos. As such, acceptance of the idea of community engagement is growing amongst health researchers. The cynical view of these new circumstances would suggest that researcher interest is merely following the money, but equally potent has been the impulse amongst many in the research community to endorse community engagement as a way to give more voice and power to patients and communities in the domains of health and healthcare, and to address devastating health disparities that diminish the lives of so many. Given the holistic lens and the attention paid to power dynamics in research that characterise much of current anthropol- 
ogy, anthropologists have a crucial role to play in this process.

\section{Meeting the Challenges of \\ New Health Research Realities}

While the beginning of a paradigm shift in health research is a new reality that offers enormous opportunities, this new reality also requires a host of attitudes, skills, approaches, considerations, relationships, and ethics that are often not well understood by community stakeholders or by researchers, including many anthropologists. Community stakeholders do not know how to find researchers who have the skills or interest to work on the health priorities that have been identified by community members. They may not be familiar with the particulars of designing and implementing a health research study, and they may not be aware of how to go about finding funding for health research, what it takes to create a competitive proposal, requirements for certification regarding human subjects or individual health information protections, or the nature of scientific approaches. There is an academic culture within universities that many community members find to be particularly alien, impenetrable or even hostile.

Similarly, health researchers frequently have no idea about how to connect with patients, communities, or community organisations. Despite the fact that anthropologists are more likely to have connections in a community, they are also at a particular disadvantage because many people see anthropology as irrelevant, academic, jargon-filled musing-which of course is a prescient indictment of much academic work. When people outside of the university find out that Author \#1 (Page-Reeves) is a PhD anthropologist, she has more than once been asked, 'So what skills do you actually have?' Convincing community members that university researchers of any sort have skills that could be used in any meaningful way in the community continues to be a challenge. And if researchers do manage to find a way to connect with the community, they often lack an understanding of community dynamics that need to be considered or the skills to work effectively and appropriately in a community context. While there are disciplines, such as anthropology or nursing, that have a tradition of working collaboratively in or with communities, investigators who never previously thought about or considered community engagement as a philosophical or methodological dimension of research are being confronted by emerging circumstances in research funding and evolving requisites for research design and recruitment. The need for researchers, including anthropologists, to develop knowledge, skills and strategies for navigating complex social and cultural dimensions of conducting research both in and with communities has now become imperative.

\section{Tips for Community-Engaged Health Research}

Because of the success that we have had creating a community-university partnership for health research in Albuquerque, New Mexico, we are routinely approached for advice by patients, community members, representatives of community organisations, researchers of all types, and even our funders enquiring about how we went about establishing our partnership and about what steps we would suggest that others take to develop something similar. On both sides of the research equation, people are looking for guidance. A number of valuable studies have identified useful strategies for developing relationships for community-engaged health research (e.g. Darling et al. 2015; Jewett-Tennant et al. 2016). Particularly interesting for health research is emerging literature about patient engagement in research and strategies for developing patient-engaged research practices (e.g. PageReeves et al. 2013a; Wallerstein et al. 2017; Woolf et al. 2016). The discussion below uses our own experience to build on the frameworks proposed in these works to offer concrete tips in plain language for steps that can be taken and strategies that can be used to build capacity for community-university partnerships for community organisations and researchers in prepartnership and early partnership stages.

We would like to note that the plain language piece of our recommendations should not be taken lightly. We do not just mean plain in a superficial way or in relation to the way we present the information below in this article. Anthropology has a ridiculous and offputting tendency to use obscurantist, obfuscatory and jargon-filled rhetoric that is impenetrable to most people, including other anthropologists (e.g. see presentation titles, descriptions and abstracts from almost any large anthropology conference). When working in a community-engaged project, being aware of language power issues and tempering academic jargon is a cardinal rule.

\section{Background}

We have developed a strong community-university partnership for research. Author \#2 (Regino) is a lo- 
cally well-known, vocal and highly respected community organiser and advocate in Albuquerque, New Mexico. She has worked for more than 20 years on critical health issues that affect the lives of Latino families from low-income households and the particular challenges faced by immigrants. She is a certified interpreter/translator and has years of experience as a community health worker (CHW). Author \#1 (Page-Reeves) is a cultural anthropologist with training in political economy. She is on the faculty in the Department of Family and Community Medicine at the University of New Mexico (UNM) in the Office for Community Health and has an extensive network of community collaborators as a result of her work inside and outside of the university on issues related to poverty, food insecurity, diabetes, local food systems, nutrition, food stamp policy, education, the built environment and social determinants of health.

In 2009, Page-Reeves was collaborating with East Central Ministries (ECM) on a youth gardening project, and she was on site for a meeting. ECM is a faithbased nonprofit organisation that operates a variety of programmes to support the Latino immigrant community, including a community garden and One Hope Centro de Vida Health Center, a CHW-run health clinic in Albuquerque's International District. Before the meeting started, a CHW who knew Page-Reeves told her that diabetes had become a huge problem for them at the clinic and that they needed help finding a way to do something about it. Page-Reeves took that request and worked with her colleague, Shiraz Mishra, at UNM to obtain a grant from the university's Clinical and Translational Science Center to work with One Hope to conduct community-engaged research to find out what people thought were the things that put them at risk for diabetes in this community and what they thought should be done. Regino was hired as the project research coordinator. We created a Community Advisory Board made up of diabetes patients and caregivers for people with diabetes, we conducted interviews and focus groups with community members, and we administered a survey with a blood draw to test for A1c with 100 people. Regino took the results of our research (Page-Reeves et al 2013a; Page-Reeves et al. 2013b) and incorporated them into an innovative diabetes programme she created at One Hope. In 2014 and 2015, we collaborated to receive two Pipeline to Proposal planning grants from the PatientCentered Outcomes Research Institute (PCORI) and subsequently, in 2016, we received a full PCORI award for research (Page-Reeves et al. 2017b).
As we have developed our research partnership over the years, we have paid close attention to issues of cultural appropriateness, equity in funding and project leadership, co-learning, 'powered' contexts and language, intellectual humility, inclusion, and shared intellectual authorship. Through this work, we have discovered dynamics involved in engaging community members and patients in research about which we had not been aware (Page-Reeves at al. 2018), and we have learnt what it takes to build a strong relationship between community partners and individuals from an academic setting. We believe that the lessons we have learnt can be helpful to others interested in community-engaged research design.

\section{Pre-Planning for Community Organisations}

For many patients, community members and community organisations, a university may appear to be an enormous labyrinth with mysterious internal divisions related to discipline, clinical training, teaching responsibilities, and separate research and tenure professional tracks that cross and overlap in odd and often contradictory ways. Community stakeholders often have no idea about how to go about identifying researchers or potential research partners within academic institutions. For anthropologists, this is exaggerated by the fact that many outside of anthropology do not understand what an anthropologist is or what one does-and so would not be likely to think of anthropologists as potential partners. And in reality, throughout the university individual researchers tend exist in silos or work bubbles where they are not connected to or necessarily even aware of each others' work. Becoming involved in research requires that community stakeholders identify potential research partners, meet with them and develop a partnership to conduct an unfunded study or to apply for research funds.

\section{Identify a Researcher(s)}

- Ask for help from your local community health council or community health coalition. It is our experience that these groups often have connections with some university researchers. Even if the individuals who have the direct connection with the health council or health coalition are not the right people, they may be able to suggest others and facilitate contact with them.

- Some universities have websites that list researcher interests. You could use these electronic resources 
to identify a potential researcher and then contact them for more information.

- Check with your local university to see whether there are departments that support service-learning or civic engagement courses. These programmes are often interested in establishing ongoing relationships in the community for their students to do small research projects. This is a good way to connect in with the university, and student projects can generate excellent preliminary data or serve as a background assessment to support the development of a larger research project.

\section{Request a Meeting with a Researcher(s)}

- After you identify an individual researcher(s), contact them and invite them to come to your site and meet with your staff and community members.

- Offer to host student projects at your site.

- Inform the researcher(s) about what your organisation or community does and about the specific issues of concern to you.

- Invite the researcher(s) to give a presentation at your site to your staff or community members on a particular health issue of interest to you or on their research.

- Ask for researcher(s) to help you and your organisation better understand what is entailed in collaborating on research.

Pursue a Partnership with a Researcher(s)

to Apply for Research Funds

- Discuss types of funding and timelines.

- Be sure that your organisational leadership is informed that you are discussing the possibility of participating in research, and make certain that they are onboard. Some people are wary about becoming involved in research, and it is important to keep leadership in the loop.

- Similarly, inform your community members or stakeholders that you are engaged in this process of working with a researcher(s) to develop a research project and possibly to apply for funding. Engage in a dialogue if there is disagreement.

- Make sure that anyone who needs to be involved in budget discussions is included in meetings you have with researchers. Research budgets can be complicated, and there needs to be sufficient communication regarding budget line items and priorities. There are things that research grants fund and those that they explicitly do not fund. Often the activities that the community wants to see funded are not allowable. Having these conversations early on in the process can avoid misunderstandings.
- Make sure that everyone is aware that it is very difficult to get funded for research. You may work really hard on a research proposal and not be successful - but that is part of the process. If you prepare people ahead of time, rejection will not seem so bad.

- Make sure that they also understand that getting the funding and doing the research do not happen quickly. Many times, communities and community organisations are not aware of how long it takes to develop a proposal, to hear if it was funded, and then to complete the research - and that often these steps need to be repeated for subsequent phases of a research project.

- Require that funding and leadership are shared equitably amongst community partners and researchers when designing your project.

\section{Pre-Planning for Researchers}

While researchers may be familiar with the 'ins and outs' of designing a research study and getting it funded, they may not know how to develop partnerships for community-engaged research. We are asked all the time about how we developed our partnership and are told by other researchers that they see the process as daunting. We often tell them that it is not really 'rocket science', and that is it rather all about relationship-building. For anthropologists, this may not be too intimidating, but we do recognise that this is easier said than done for researchers who are not accustomed to having to work collaboratively with people outside the university, or who have never needed to establish partnerships in the community or engage in extra actions before beginning the actual research process from an idea that they developed without input from the community. We therefore propose a few simple steps:

\section{Get to Know Each Other}

- Identify individuals and community organisations that might be interested in the work you do or the things you would like to work on. Your local community health council or public health department would be a great place to start. They may be familiar with many community organisations, agencies and coalitions that work on the issues that you are concerned about.

- Networking with the people and organisations you identify is fundamental. You can start by inviting the individuals you identify to coffee so that you can learn about what they do. 
- Ask to visit their organisations to get an on-site tour.

- Getting others to know you is really important. If you want to partner with people and organisations in the community, you have to help them understand who you are and why they should bother. They need to know what you do and what your expertise entails, but they also need to see you as someone who has the right character for community work. You need to demonstrate that you are approachable, that even though you have an advanced degree you are not 'full of yourself'. Demonstrating that you care about the issues they care about and helping them see that you are someone that they can talk to and interact with is a big part of building the trust you need to establish a partnership for research.

\section{Attend Community Meetings Regularly}

- Identify community meetings where you might generally find people interested in your work or who work on issues you care about - examples include community health councils, community health coalitions, neighbourhood associations and groups which meet around a particular health or health promotion issue such as diabetes or teen pregnancy.

- Showing up to meetings regularly demonstrates that you are active, engaged, interested and responsible. This is important because researchers have a reputation for being 'here today, gone tomorrow' when the funding runs out.

- Give out your card liberally at these meetings so that people know how to contact you.

- Offer to give a community presentation on a health issue and/or on your research using non-academic language, and distribute a brief, non-academic handout about the issue or your work.

- Become involved in community issues by serving on a community committee or volunteering to take on a task. This demonstrates that you are interested in more than just using the community to do research - you care about the community.

- And using your professional expertise to actually contribute to the well-being of the community is a key part of engagement. University-educated researchers generally have the skills to write the type of grants that community organisations need to submit to get funding for their operational activities. You can help them write grants to support their work. You can also use your professional expertise and authority to advocate for community issues or resources with local policymakers or governmental bodies.

\section{Make Specific Connections for Research}

- Once you identify a community partner that you think would fit well with your own interests, contact them and ask to set up a meeting to learn more about what they do and to tell them about what you do.

- Importantly, a key conversation is finding out what things they are interested in knowing or what they need help with. This conversation will help you frame or define the potential research topic or question. In the old model of investigator-driven research, a researcher could sit in their office and develop a project. Community-engaged research requires that you work with partners to find out what they want to know. The project you develop together needs to be of explicit benefit or interest to them, so you may have to find a way to creatively integrate your own interests or the topics of interest to funders into your project. This is a foundational piece of a community-university partnership. Both partners need to be excited about the concept, and it has to have scientific relevance and a rigorous design if you have any hope of being funded. Finding this balance is generally possible, but it often takes a certain amount of creative thinking.

- Offer to give a talk about a health issue and/or about your research - and give them a handout written using non-academic language.

- Help them make connections they may not know how to make with other researchers, other organisations, policymakers or local funders.

- Help them identify new sources of programme funding, or write and submit non-research programme grants to support their organisational work in the community.

Do not just 'Involve' Your Community Partner in Research

- With the rising popularity of community-engaged research, we hear a lot about involving the community in all phases of research. But this language still fails to honour the real meaning of partnership. If you 'involve' your partners, then it is you 'allowing' them to have a role. Instead, your partnership should be one of co-equals where you learn as much from the engagement as they do (Dadwal et al. 2017).

- It is also important to acknowledge that your partners have extensive expertise that is not related to academic degrees or titles. This is an important component of building a co-equal relationship.

- When designing a project, ensure the equitable distribution of resources and shared leadership. If 
appropriate, have your main community partner be a PI (principal investigator) or Co-PI on the project rather than just a community collaborator or a recruitment site partner. And in relation to decision-making and leadership, make sure that this is more than just a title.

- Involve partners in the dissemination of research results through presentations in both community and professional venues. Have them take the lead on presenting. Giving them an opportunity to share why they think the research is important or relevant can be more powerful than having someone from the university present it.

- Too often, researchers fail to realise that working in/with communities leaves a social footprint. It is important to recognise before you launch a partnership that the relationship you create should not end with cycles of funding. It is a long-term commitment. It is important to assure the community partner that, if a proposal for funding does not get funded, you are vested in this new partnership and truly believe in the research project you both want to carry out and will continue to seek funding for it.

\section{Community Benefits of Research Partnerships}

Despite the challenges involved in establishing a research partnership and participating in a research study, there are concrete benefits that can accrue to community organisations:

- Research partnerships can provide access to resources that may support staff time or even provide operational support through indirect funding. Under certain circumstances, research funding can fund the implementation of community services.

- Research can provide information to address issues of interest to your community or to your organisation.

- You can use the results of research to improve your organisational or programme operations.

- Working collaboratively on a research project can develop staff skill sets and capacity.

- Your collaborative work could produce evidence needed to get policymakers to support a community priority or effort.

\section{Researcher Benefits of Research Partnerships}

Similarly, even though creating and maintaining partnerships in the community can be time-consum- ing and require the development of new skills, researchers also benefit from community engagement in research.

\section{Operational benefits}

When you work collaboratively with community partners, the people you work with will likely:

- Understand things about the community context and about participants' lives that may influence the implementation or outcome of your project.

- They will know culturally appropriate methods for recruiting and be able to contact and connect with participants.

- They will have trust and rapport with participants that will make it more likely that they can recruit them.

- They will know how to troubleshoot problems that inevitably arise in conducting research in communities.

- They will understand dimensions of the research and have insights into the health issue of concern that you may not have thought about but that may have significant implications for your project.

\section{Scientific benefits}

There are also scientific benefits to community engagement practices (Balazs and Morello-Frosch 2013):

- The research is better designed to be appropriate to the context.

- The overall research question is more fine-tuned to include patient and community perspectives.

- The questions you plan to ask people can be refined to be the right questions asked in the right way.

- Analysis and interpretation of data is more likely to be accurate and innovative when you have those community perspectives.

- Your results are more likely to be meaningful in relation to real-life use.

- Results are more likely to be disseminated and used, including potentially being able to be used directly by your community partner.

\section{Discussion}

As Jennifer Gallivan and colleagues (2012) discuss, and as anthropologists well know, community engagement in research is complex. The methods, mechanisms, and practices of engagement can take many forms. However, we are at a critical juncture. Norman Denzin's (2017) insightful analysis of how global politics influence epistemologies in academic research 
is a chilling reminder of the need for a holistic lens in thinking about the broader dynamics of academic production and for locating ourselves and our work in a political landscape. He brilliantly untangles the powerful alliance between conservative regimes and biomedical models of research, and the march over the past 20 years towards lithifying 'evidence' produced using quantitative, positivist, exclusionary methods as the gold standard, or even the only standard, for defining scientific 'truth'. He describes a 'paradigm war' in which a narrowly defined methodological conservatism undermines the legitimacy of qualitative enquiry and other ways of knowing as 'unscientific' while ironically rejecting findings that were developed by professionals using 'scientific' standards, manipulating facts that are inconvenient, and promoting pseudoscience to support political agendas (in the US, for example, the controversial No Child Left Behind educational policy, and internationally for anti-climate-change narratives).

Denzin's concern with attempts to discipline and regulate qualitative enquiry specifically in educational research is echoed by medical anthropologists and other researchers who contest epistemic tendencies in health research towards narrowly defined scientific enquiry that privileges quantitative methods and excludes the idea that there is any other legitimate way of knowing about or perceiving the world (Cook 2012; Hammersley 2008, 2017; Krumeich et al. 2001; Lambert and McKevitt 2002). As described above, we have experienced these dynamics in the pursuit of our own research. More broadly, in qualitative health research, including work done by anthropologists, there has been a move towards requiring multiple, repeated comparisons of transcripts with audio recordings, processes to produce intercoder reliability, or insistence on a large or 'representative' sample as necessary for scientific rigour and 'power' in any scientific analysis. And community engagement has traditionally been rejected as legitimate in research design. This inappropriately imposes the use of a positivistic, quantitative paradigm in the analysis of data that requires a more complex, interpretive approach. The literature has demonstrated that it is not necessary to go to such excessive lengths (such as comparing transcripts three times with the recording) or having multiple levels of intercoder reliability. Those things waste resources and have not been shown to improve the scientific quality of or to make a difference in findings. Kay Cook (2012) made the point that she does not take a second reader with her to the library when she does a literature review to make sure that her interpretation of the literature is 'agreed upon'. One could argue that having multiple coders can actually introduce multiple streams of subjectivity - and having multiple subjective perspectives does not somehow magically make research objective. It is possible to offer 'proof' in other ways, such as Martyn Hammersley's (2008) criteria for scientific research based on plausibility, credibility and relevance. It is one thing if you are doing team science and you want a variety of people to be involved in discussing the interpretations. That can be a good thing. But to call this 'intercoder reliability' and to define it as required merely emboldens attempts to discount, exclude and prohibit more holistic approaches to data analysis. Helen Lambert $(2006,2009)$ discusses how current notions of evidence and 'evidentiary truths' that rely on a narrow definition of scientific evidence have had a damaging impact on health research. 'Evidencebased' models and practices have become ensconced as metrics required by research funders and journal reviewers. In the emerging research context, scientific 'facts' can only be produced using accepted 'rigorous' methods. Hammersley (2017) goes further, rejecting the partitioning of the research world into contrasting and often antagonistic quantitative and qualitative camps as detrimental to the development of meaningful analysis.

And it is in this context that we find the clamour about community engagement in research. Patients, community members and communities have raised questions about whose evidence is being used as the metric. If research questions are developed inside the heads of researchers, research projects are implemented by researchers on participants, and analysis of data is conducted excluding perspectives, experiences, or ideas that do not emanate from narrowly defined academic scientism, to what extent is the 'evidence' actually valid or meaningful? And how problematic is it that this evidence is being used to enact policy or to justify political narratives? At this critical juncture, it is imperative that in health research we nurture a knowledge, relationship and resource infrastructure for equitable, communityengaged health research partnerships that can provide an opportunity for alternative perspectives and voices to be expressed, listened to and incorporated into models of research and policy. Community engagement in health research can give voice to patients and communities in a way that disrupts power dynamics that limit our understanding of the root causes of health disparities and health problems or curtail our ability to envision new ways of thinking about solutions, and it can construct alternative futures based in paradigms of equity and social justice. 
Although often under-appreciated in health research, an anthropological lens grounded in contextual rigour, emphasising holistic integration in research design and focus, and approaching seemingly static norms and realities as fluid and dynamic, can be used more effectively towards these ends. Helen Lambert and Christopher McKevitt (2002) propose that the anthropological paradigm provides a way for us to see things from other people's perspectives - to see the relational. They write that the 'key anthropological contribution to health research lies in its empirically based grasp of the context specific nature of social processes' or its capacity to 'question the apparently familiar' (2002: 212). This epistemological stance allows anthropologists to reconfigure boundaries of empirical investigation. Anja Krumeich and colleagues (2001: 126) suggest that the anthropological perspective facilitates the interpretation of what people say and do and why they say and do it (or not). Combining community-engaged approaches in health research with the ethnographically inspired, holistic framework from anthropology has the capacity to further our ability to conceptualise social, behavioural and cultural processes and to develop reliable and grounded measures to better capture dynamics that influence health and well-being and produce health disparities.

\section{Conclusion}

Many of us have advocated for years for expanding opportunities for and acceptance of communityengaged principles and practices in health research, and developed expertise in this area. In the unfolding global context for health research, there are now new opportunities emerging for resources to support community-engaged ethics and practices; at the same time, we recognise the urgency of contesting political and epistemic tendencies to limit the parameters of knowledge production. Despite movement towards community engagement in research, too often the reality of engagement is merely 'tokenism' (Ocloo and Matthews 2016) that does not actually engage or empower people in any meaningful way. And Jonathan Tritter (2009) warns that such tokenism provides fertile ground for hegemonic healthcare reformist agendas to turn engagement and participation into little more than a mechanism for bureaucratic manipulation of patients within a commercial healthcare system. There are, however, possibilities for change, and anthropology can be part of the solution. Anthropologists have particular skills and experiences that can contribute to defining the terms of engagement for realistic and meaningful community-university research partnerships that will expand the ways that we define and think about health and wellness. It is now incumbent upon those of us with experience in designing and implementing community-engaged research projects to disseminate the knowledge and skills that are required for equitable partnerships to develop and succeed.

Janet Page-Reeves, PhD, is a cultural anthropologist with training in political economy and gender theory, and she is an Associate Professor in the Office for Community Health in the Department of Family and Community Medicine at the University of New Mexico. She has a strong and unique background in theoretically grounded research and communitybased applied work. Her research is infused with an appreciation for the salience of using a holistic approach as a foundation for understanding complex social issues. She has extensive research, applied and community experience working on issues related to social determinants of health, cultural adaptations of interventions, patient-community engagement and poverty. Themes of interest include food insecurity, food systems, food allergy, diabetes, STEM education, educational outcomes, identity, gender, and community health workers (CHWs).

Email: jpage-reeves@salud.unm.edu

Lidia REgINo, BA, a native Spanish speaker, has lived in Albuquerque, New Mexico, for about 31 years. She has three children and two grandchildren. She received a Bachelor's degree in University Studies from the University of New Mexico. Lidia has been a community health worker (CHW) and community advocate for more than 20 years, working in areas such as health, education, immigrant rights and public policy. For many years, she worked as the director of One Hope Centro de Vida Health Center. She is currently Health Extension Regional Officer (HERO) with the Office for Community Health at the University of New Mexico. Email: lregino@salud.unm.edu

\section{Note}

1. For example, in the United States: National Institutes of Health (NIH) (PA-13-209) Innovative Measurement Tools for Community Engaged Research Efforts; National Institutes of Health / National Institute of Nursing Research (PA-14-142) Community 
Partnerships to Advance Research; American Cancer Society Midwest Division (CDC-RFA-PS14-1406) Pilot and Exploratory Studies Using CommunityBased Participatory Research (CBPR) to Achieve Cancer Health Equity; and Centers for Disease Control (CDC) (CDC-RFA-PS14-1406) Community Approaches to Reducing Sexually Transmitted Disease. And in the United Kingdom: the Clinical Research \& Innovation Office Lay Advisory Panels and PPI team; National Institute for Health Research (NIHR) Research Design Service for Yorkshire \& the Humber (RDS YH) funding awards; NHS INVOLVE; and People in Research, Oxford Clinical Trials Research Unit.

\section{References}

Balazs, C. L. and R. Morello-Frosch (2013), 'The Three Rs: How Community-Based Participatory Research Strengthens the Rigor, Relevance, and Reach of Science', Environmental Justice 6, no. 1: 9-16. doi:10.1089/env.2012.0017.

Bangstad, S., I. Ahmad, I. Feldman, J. R. Bowen, A. Haugerud, D. H. Price and M. L. Fernando (2017), 'Anthropological Publics, Public Anthropology', HAU: Journal of Ethnographic Theory 7, no. 1: 489-508, doi:10.14318/hau7.1.034.

Brett, J., S. Staniszewska, C. Mockford, S. Herron-Marx, J. Hughes, C. Tysall and R. Suleman (2014), 'Mapping the Impact of Patient and Public Involvement on Health and Social Care Research: A Systematic Review', Health Expectations 17, no. 5: 637-650.

Cook, K. (2012), 'Reliability Assessments in Qualitative Health Promotion Research', Health Promotion International 27, no. 1: 90-101. doi:10.1093/heapro/dar027.

Dadwal, V., L. Basu, C. M. Weston, S. Hwang, C. Ibe, L. Bone, R. T. Boonyasai, J. Gentry, L. Purnell and A. W. Wu (2017), 'How Co-Developed Are Community and Academic Partnerships?', Progress in Community Health Partnerships 11, no. 4: 387-395. doi:10.1353/cpr.2017.0046.

Darling, M., F. Gonzalez, K. Graves, V. B. Sheppard, A. H. de Mendoza, K. G. Leventhal and L. Caicedo (2015), 'Practical Tips for Establishing Partnerships with Academic Researchers: A Resource Guide for Community-Based Organizations', Progress in Community Health Partnerships 9, no. 2: 213-221. doi:10.1353/cpr.2015.0042.

Denzin, N. K. (2017), Qualitative Inquiry Under Fire: Toward a New Paradigm Dialogue (London: Routledge).

Gallivan, J., K. Kovacs Burns, M. Bellows and C. Eigenseher (2012), 'The Many Faces of Patient Engagement', Journal of Participatory Medicine 4: e32.
Hammersley M. (2008), Questioning Qualitative Inquiry: Critical Essays (London: Sage Publications).

Hammersley, M. (2017), 'Deconstructing the QualitativeQuantitative Divide', in J. Brannen (ed.), Mixing Methods: Qualitative and Quantitative Research (London: Routledge), 39-55.

Haywood, K., J. Brett, S. Salek, N. Marlett, C. Penman, S. Shklarov, C. Norris, M. J. Santana and S. Staniszewska (2015), 'Patient and Public Engagement in Health-Related Quality of Life and Patient-Reported Outcomes Research: What Is Important and Why Should We Care? Findings From the First ISOQOL Patient Engagement Symposium', Quality of Life Research 24, no. 5: 1069-1076.

Jewett-Tennant, J., C. Collins, J. Matloub, A. Patrick, M. Chupp, J. J. Werner and E. A. Borawski (2016), 'Partnership Among Peers: Lessons Learned from the Development of a Community OrganizationAcademic Research Training Program', Progress in Community Health Partnerships 10, no. 3: 461-470. doi:10.1353/cpr.2016.0052.

Kania, J. and M. Kramer (2011), 'Collective Impact', Stanford Social Innovation Review 9, no. 1: 36-41. https://ssir.org/articles/entry/collective_impact.

Krumeich, A., W. Weijts, P. Reddy and A. Meijer-Weitz (2001), 'The Benefits of Anthropological Approaches for Health Promotion Research and Practice', Health Education Research 16, no. 2: 121-130.

Lambert, H. (2006), 'Accounting for EBM: Notions of Evidence in Medicine', Social Science E Medicine 62, no. 11: 2633-2645.

Lambert, H. (2009), 'Evidentiary Truths? The Evidence of Anthropology Through the Anthropology of Medical Evidence', Anthropology Today 25, no. 1: 16-20.

Lambert, H. and C. McKevitt (2002), 'Anthropology in Health Research: From Qualitative Methods to Multidisciplinarity', British Medical Journal 325, no. 7357: 210-213.

Landi, N. (2017), "'Pleasure Is Not in the Science Programme!": When Anthropology Engages with Sex Education for Teenagers', Anthropology Matters 17, no. 1.

Ocloo, J., and J. Matthews (2016), 'From Tokenism to Empowerment: Progressing Patient and Public Involvement in Healthcare Improvement', BMJ Quality $\mathcal{E}$ Safety 25, no. 8: 626-632.

Page-Reeves, J. (2018), 'A Bundle of Barriers: University Infrastructural Impediments to Patient-Engaged Health Research', paper to be presented at the Annual Meeting of the Southwest Anthropological Association (SWAA), Fresno, California, May 4-5. Page-Reeves, J., A. Marin, M. Bleecker, M. Moffett, K. DeerInWater, S. EchoHawk and D. Medin (2017), 
'From Community Data to Research Archive: Partnering to Increase and Sustain Capacity within a Native Organization', Gateways: International Journal of Community Research and Engagement 10: 283-297. doi:10.5130/ijcre.v10i1.4947.

Page-Reeves, J., S. Mishra, J. Niforatos, L. Regino, A. Gingrich and R. Bulten (2013a), 'An Integrated Approach to Diabetes Prevention: Anthropology, Public Health, and Community Engagement', Qualitative Report 18: 1-22.

Page-Reeves, J., J. Niforatos, S. Mishra, L. Regino, A. Gingrich and R. Bulten (2013b), 'Health Disparity and Structural Violence: How Fear Undermines Health Among Immigrants at Risk for Diabetes', Journal of Health Disparities Research and Practice 6, no. 2: 30-48.

Page-Reeves, J., L. Regino, H. McGrew, M. Tellez, B. Pedigo, A. Overby, A. Cunningham, S. Tigert and M. Burge (2017a), 'Collaboration and Outsidethe-Box Thinking to Overcome Training-Related Challenges for Including Patient Stakeholders as Data Collectors in a Patient-Engaged Research Project', Journal of Patient Experience 5, no. 2: 88-91. doi:10.1177/2374373517729506.

Page-Reeves, J., L. Regino, C. Murray-Krezan, M. Bleecker, E. Erhardt, M. Burge, E. Bearer and S. Mishra (2017b), 'A Comparative Effectiveness Study of Two Models for Culturally Competent Diabetes Self-Management Programming for Latinos from Low-Income Households', BMC Endocrine Disorders 17, no. 46. doi:10.1186/ s12902-017-0192-4.
Page-Reeves, J., L. Regino, M. Tellez, B. Pedigo and E. Perez (2018), 'Engaging Latino Patients in Diabetes Research: What We Are Learning', Practicing Anthropology 40, no. 3: 35-40.

Shakya, M. and J. Clammer (2017), 'Economic Anthropology and Development Alternatives: Rethinking and Re-Politicizing Theory and Practice', Dialectical Anthropology 41, no. 2: 87-96, doi:10.1007/ s10624-017-9453-x.

Towe, V. L., L. Leviton, A. Chandra, J. C. Sloan, M. Tait and T. Orleans (2016), 'Cross-Sector Collaborations and Partnerships: Essential Ingredients to Help Shape Health and Well-Being', Health Affairs 35, no. 11: 1964-1969. doi:10.1377/hlthaff.2016.0604.

Tritter, J. Q. (2009), 'Revolution or Evolution: The Challenges of Conceptualizing Patient and Public Involvement in a Consumerist World', Health Expectations 12, no. 3: 275-287.

Trujillo, M. D. and A. Plough (2016), ‘Building a Culture of Health: A New Framework and Measures for Health and Health Care in America', Social Science $\mathcal{E}$ Medicine 165: 206-213. doi:10.1016/j.socscimed .2016.06.043.

Wallerstein, N., B. Duran, J. Oetzel and M. Minkler (eds.) (2017), Community-Based Participatory Research for Health (Third Edition) (Hoboken, NJ: Jossey-Bass \& Pfeiffer Imprints).

Woolf, S. H., E. Zimmerman, A. Haley and A. H. Krist (2016), 'Authentic Engagement of Patients and Communities Can Transform Research, Practice, and Policy', Health Affairs 35, no. 4: 590-594. doi:10.1377/ hlthaff.2015.1512. 